\title{
Cucumber mosaic virus Infection Transiently Breaks dsRNA-Induced Transgenic Immunity to Potato virus $Y$ in Tobacco
}

\author{
Neena Mitter, Emy Sulistyowati, and Ralf G. Dietzgen \\ Queensland Department of Primary Industries, Agency for Food and Fibre Sciences, Agricultural Biotechnology and \\ Cooperative Research Centre for Tropical Plant Protection, The University of Queensland, St. Lucia Qld 4072, Australia
}

Submitted 10 April 2003. Accepted 14 June 2003.

\begin{abstract}
Post-transcriptional gene silencing (PTGS), an intrinsic plant defense mechanism, can be efficiently triggered by double stranded (ds)RNA-producing transgenes and can provide high level virus resistance by specific targeting of cognate viral RNA. The discovery of virus-encoded suppressors of PTGS led to concerns about the stability of such resistance. Here, we show that Cucumber mosaic virus (CMV) is able to suppress dsRNA-induced PTGS and the associated Potato virus Y (PVY) immunity in tobacco. CMV suppression supported only a transient PVY accumulation and did not prevent recovery of the transgenic plants from PVY infection. CMV inoculation resulted in strongly increased transgene mRNA levels due to suppression of PTGS, but accumulation of PVY-specific small interfering (si)RNA was unaffected. However, PVY accumulation in previously immune plants resulted in increased PVY siRNA levels and transgene mRNA was no longer detected, despite the presence of CMV. Transgene mRNA returned to high levels once PVY was no longer detected in CMVinfected plants. Recovered and chronically CMV-infected tissues were immune to further PVY infection.
\end{abstract}

Additional keywords: PTGS suppression, transgenic virus resistance.

Post-transcriptional gene silencing (PTGS) is an evolutionary conserved mechanism that recognizes double-stranded (ds)RNA as a signal to trigger the cytoplasmic sequence-specific degradation of cognate RNA (Matzke et al. 2001; Sharp 2001; Waterhouse et al. 2001). It is associated with the production of small interfering (si)RNAs (21 to $25 \mathrm{nt}$ ) of both sense and antisense orientation derived from the input dsRNA. Such siRNAs have been detected in vivo in plants (Hamilton and Baulcombe 1999), Caenorhabditis elegans (Parish et al. 2000), Drososphila melanogaster (Zamore et al. 2000), trypanosomes (Djikeng et al. 2001), and mammals (Carmell et al. 2003). PTGS can be triggered locally and spread systemically throughout the plant via a mobile silencing signal that can cross a graft junction (Fagard and Vaucheret 2000). Dicer, an ATP-dependent RNase III-like ribonuclease specifically cleaves dsRNA into siRNAs (Bernstein et al. 2001), which appear to act as guide RNAs that target an associated nuclease complex, called RISC (RNA induced silencing complex)

Corresponding author: Ralf G. Dietzgen; DPI Queensland Agricultural Biotechnology Centre; Telephone: (61) 73346 2703; Fax: (61) 73346 2727; E-mail: ralf.dietzgen@dpi.qld.gov.au.
(Hammond et al. 2000), to homologous RNAs through sequence complementarity (Bass 2000).

In higher plants, PTGS functions as a natural antiviral defense mechanism (Baulcombe 1999; Carrington et al. 2001; Ding 2000; Dougherty and Parks 1995; Marathe et al. 2000; Voinnet 2001). It can be induced by highly transcribed sense transgenes (Que et al. 1997; Vaucheret et al. 1997) or by transgenes coding for dsRNA, i.e., inverted repeat sequences separated by a stuffer (Chuang and Meyerowitz 2000; Sijen et al. 2001b; Stam et al. 1998; Waterhouse et al. 1998). A branched pathway model for sense and dsRNA-induced PTGS has recently been proposed (Beclin et al. 2002). According to this model, dsRNA is the branch point between PTGS induction by sense- or dsRNA-encoding transgenes. Sense transgenes appear to give rise to dsRNA by steps involving AGO1, SGS2/SDE1, SGS3, and SDE3 proteins, whereas these are dispensable for dsRNA-induced PTGS. Transgenes encoding virus-derived dsRNA have been reported to be more efficient in conferring high-level virus resistance in plants than sense or antisense viral transgenes (Wang et al. 2000; Wesley et al. 2001). DsRNA-encoding transgenes are likely to become the preferred choice for providing genetically modified virus resistance in the future because a single copy is sufficient to achieve immunity, no viral proteins are expressed, short incomplete sequences can be used, and targeted RNA is degraded in almost all independently transformed plants.

The existence of suppressors of PTGS, encoded by RNA and DNA viruses (Voinnet et al. 1999), poses questions about the stability of PTGS-based resistance in transgenic plants (Mitter et al. 2001). Experiments with transgenic plants expressing the helper component-protease of potyviruses show that it suppresses maintenance of PTGS and results in the elimination of siRNAs but does not interfere with either the production and intercellular spread of the silencing signal or silencing-associated DNA methylation (Llave et al. 2000; Mallory et al. 2001). In contrast, the $2 \mathrm{~b}$ protein of Cucumber mosaic virus (CMV) does not reverse already established PTGS; however, the signal-mediated spread of PTGS into new tissues is suppressed (Brigneti et al. 1998; Li and Ding 2001; Lucy et al. 2000). Inhibition of the mobile silencing signal, alteration in the methylation of transgene DNA in the nucleus, and reduction in the level of siRNAs by transgenically expressed $2 b$ protein has recently been reported for sense transgene-induced silencing of the $\beta$-glucuronidase (GUS) reporter gene (Guo and Ding 2002).

In this scenario of plants and viruses fighting it out, plants in terms of PTGS and viruses in terms of suppression of PTGS, our aim was to gain insight into the mechanism of PTGS suppres- 
sion, which may lead to loss of resistance. So far, the mechanism of PTGS suppression by a virus-encoded suppressor has been examined for either agroinfiltration-induced silencing or sense transgene-induced silencing. In contrast, we have investigated the suppression of dsRNA-induced PTGS by CMV, using a tobacco line carrying a single copy dsRNA-encoding transgene to target Potato virus Y (PVY), similar to the ones shown to be potent initiators of PTGS (Smith et al. 2000). Preliminary investigations revealed that the immunity to PVY in this transgenic line can break down upon infection with CMV (Mitter et al. 2001). The present investigation examines the suppression by CMV of dsRNA-induced PTGS over a period of six months in terms of effects on transgene transcripts and siRNA levels, as well as the extent of PVY and CMV accumulation and virus resistance. Voinnet (2001) recently pointed out that expression of suppressors outside the context of a natural virus infection, either as highly transcribed transgenes or from heterologous virus vectors, may provide an exaggerated picture of their involvement in normal infections. This adds further significance to our experimental system, because we have studied the mechanism of suppression of dsRNA-induced immunity as it may happen in a field of transgenic crops exposed to naturally occurring viruses.

\section{RESULTS}

\section{CMV interferes with PTGS}

in newly emerged leaves, making PVY-immune transgenic tobacco plants susceptible to PVY infection.

Transgenic T1 and T2 progeny tobacco plants of line \#16, which carry an inverted repeat PVY NIa transgene (Fig. 1), were immune to PVY. PVY was not detected in plants from

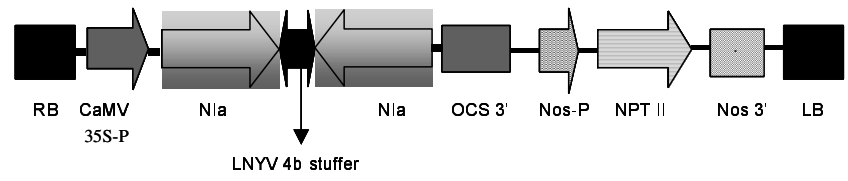

Fig. 1. Schematic representation of the Potato virus $Y$ NIa hairpin stuffer T-DNA construct present in line \#16 transgenic tobacco plants. this line at any time during the experiments in terms of both visual symptoms and enzyme-linked immunosorbent assay (ELISA), while untransformed controls showed typical PVY symptoms from 10 days after inoculation. T1 generation line \#16 plants were inoculated with CMV (C), PVY (P), and CMV followed by PVY $(\mathrm{C}+\mathrm{P})$ at various time intervals to determine the time required for PTGS to become impaired sufficiently to allow PVY replication. The leaf inoculated with CMV was designated leaf 0 and other leaves above were numbered according to their proximity to leaf 0 . PVY was inoculated on a leaf already present at the time of $\mathrm{CMV}$ inoculation (leaves 1 or 2) in the cases of $\mathrm{C}+\mathrm{P}_{0}, \mathrm{C}+\mathrm{P}_{2}$, and $\mathrm{C}+\mathrm{P}_{7}$ plants (Fig. 2). Two weeks postinoculation with $\mathrm{CMV}$ (wpiC), all $\mathrm{C}$ and $\mathrm{C}+\mathrm{P}$ line \#16 and untransformed tobacco plants were judged infected with CMV by the presence of typical mosaic symptoms, and this was confirmed by ELISA. PVY symptoms and ELISA confirmed the presence of PVY in all untransformed $\mathrm{P}$ or $\mathrm{C}+\mathrm{P}$ plants at this stage but not in any of the similarly treated immune line \#16 plants (Table 1). Thus, dsRNA-induced PVY immunity in line \#16 plants was maintained for a period of up to 2 weeks, despite the presence of CMV. However, symptoms of PVY infection were observed on some of the $\mathrm{C}+\mathrm{P}$ plants of line \#16 from three wpiC, indicating breakdown of resistance.

At six wpiC, PVY was still not detected by ELISA in leaves 1 and 2 , which were present on $\mathrm{C}+\mathrm{P}$ line \#16 plants at the time of CMV inoculation (data not shown), but PVY was detected in leaf 4 onwards in $4 / 11 \mathrm{C}+\mathrm{P}_{0}, 5 / 12 \mathrm{C}+\mathrm{P}_{2}$, and $9 / 12 \mathrm{C}+\mathrm{P}_{7}$ plants (Fig. 3). In contrast, PVY was detected in all leaves tested of similarly treated untransformed tobacco plants, irrespective of their presence or absence at the time of CMV inoculation (data not shown). The relative titers of PVY in infected line \#16 plants varied from leaf to leaf and plant to plant (Fig. 3), and PVY was detected only when CMV was also present in the same leaf (data not shown). Even though PVY was able to infect $\mathrm{C}+\mathrm{P}$ line \#16 plants, the relative PVY titers tended to be lower as compared with untransformed $\mathrm{C}+\mathrm{P}$ plants (Fig. 3). Furthermore, the movement of PVY in the transgenic plants was restricted relative to the untransformed $\mathrm{C}+\mathrm{P}$ plants. For example, only $1 / 4 \mathrm{C}+\mathrm{P}_{0}, 1 / 5 \mathrm{C}+\mathrm{P}_{2}$, and $2 / 9$ $\mathrm{C}+\mathrm{P}_{7}$ plants of line \#16 that were infected with PVY also accumulated PVY in the youngest leaf (Fig. 3, leaf 8). These obser-
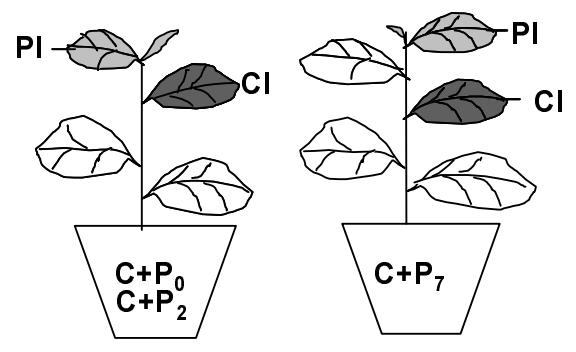

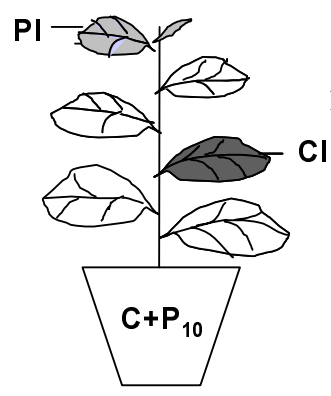

\section{respect to $\mathrm{Cl}$}

Fig. 2. Designations of tobacco leaf positions and experimental design for Cucumber mosaic virus (CMV) and Potato virus $Y$ (PVY) inoculations. CI $=$ $\mathrm{CMV}$-inoculated leaf 0 (black); PI = PVY-inoculated leaf (gray); $\mathrm{C}+\mathrm{P}_{0}=\mathrm{PVY}$ inoculated on leaf 1 on the same day as CMV; $\mathrm{C}+\mathrm{P}_{2}=\mathrm{PVY}$ inoculated on leaf 1, 2 days after CMV; $\mathrm{C}+\mathrm{P}_{7}=\mathrm{PVY}$ inoculated on leaf 2, 7 days after $\mathrm{CMV} ; \mathrm{C}+\mathrm{P}_{10}=\mathrm{PVY}$ inoculated on leaf 3 , which emerged after about 10 days of CMV inoculation. Leaves 1 and 2 above CMV-inoculated leaf 0 were present at the time of CMV inoculation; leaf 3 was the first leaf that emerged after CMV inoculation; and leaves 4 and onward are subsequent systemic leaves that emerged after CMV inoculation. 
vations indicate that PVY replication and movement was impaired to some degree in line \#16 plants, despite breakdown of immunity and the presence of CMV.

Based on the observation that longer periods of time between CMV inoculation and challenge of line \#16 plants with PVY led to a larger proportion of susceptible plants, an experiment was designed wherein PVY was inoculated on newly emerged leaf 3 ten days after $\mathrm{CMV}$ inoculation $\left(\mathrm{C}+\mathrm{P}_{10}\right)$ (Fig. 2). T2 generation plants of line \#16 were inoculated with CMV alone ( 3 plants), buffer ( 3 plants), and CMV followed by PVY (13 plants). Three plants of untransformed tobacco per treatment were used as controls. At three wpiC, PVY was detected in leaf 4 of all $\mathrm{C}+\mathrm{P}_{10}$ line \#16 plants, indicating a $100 \%$ breakdown of PVY immunity (data not shown). The reduced PVY accumulation in young leaves of plants showing breakdown of immunity (Fig. 3) prompted us to continue monitoring these plants to investigate if suppression might fail over time.

\section{PVY fails to establish a stable systemic infection in PTGS-suppressed transgenic tobacco.}

The accumulation and movement of CMV or CMV and PVY in two $\mathrm{C}$ and four $\mathrm{C}+\mathrm{P}_{10}$ line \#16 plants selected from the above experiment, as well as in similarly treated untransformed tobacco plants, was determined by ELISA of individual leaves present at 3, 5, 10, 16, 19, and 23 wpiC. Each leaf was tested only once, and the data of the entire experiment are shown in Figure 4. CMV was detected throughout in all leaves tested of untransformed tobacco (data not shown) as well as line \#16 C and $\mathrm{C}+\mathrm{P}$ plants, with $\mathrm{CMV}$ titers varying from leaf to leaf (Fig. 4). In the four $\mathrm{C}+\mathrm{P}_{10}$ plants of line \#16 that had tested PVY positive in leaf 3, PVY was detected only up to leaf 12 (plant 1), leaf 7 (plant 2), leaf 8 (plant 3), and leaf 6 (plant 4) (Fig. 4). No PVY symptoms were observed in new leaves of these plants 8 to 10 wpiC, whereas clear symptoms of both CMV and PVY persisted on all leaves of untransformed tobacco plants throughout the experiment. It therefore appears that PVY could not maintain a systemic infection in $\mathrm{C}+\mathrm{P}_{10}$ line \#16 plants, despite the continued presence of CMV. The basis for this recovery was investigated by inoculation of two fully expanded young leaves each of these recovered $\mathrm{C}+\mathrm{P}_{10}$ line \#16 plants with fresh PVY inoculum 16 wpiC. PVY did not reinfect plants at this stage and was not detected by ELISA in the inoculated or three subsequent leaves sampled two weeks postinoculation with PVY. In a repeat experiment, five different $\mathrm{C}+\mathrm{P}_{10}$ line \#16 plants that had recovered from PVY infection showed similar results when reinoculated with PVY nine wpiC. However, even $\mathrm{C}$ plants of line \#16 could not be infected with PVY, whereas PVY was able to infect mock- or CMVinoculated untransformed plants of the same age. This indicates that chronically CMV-infected line \#16 plants, as well as recovered line \#16 plants, were immune to PVY infection.
Virus infection affects transgene mRNA levels.

Quantitative real time reverse transcriptase-polymerase chain reaction (Q-RT-PCR) was used to measure transgene mRNA levels in extracts of total plant RNA. We devised QRT-PCR assays that specifically targeted either the PVY NIa hairpin sequence or the unique Lettuce necrotic yellows virus (LNYV) stuffer. Both assays detected in vitro transcripts of the transgene with similar efficiency across five orders of magnitude (data not shown). Neither NIa nor stuffer mRNA sequences were detected in leaves of mock-inoculated line \#16 plants, confirming active PTGS targeting the transgene (data not shown). Following CMV infection of five line \#16 plants, the stuffer and NIa sequences of the transgene mRNA were detected from leaf 3 onwards, but not in leaves 0, 1, and 2 (Fig. 5 , shown for one plant). Thus, both dsRNA and stuffer sequences of the transgene mRNA were detectable in leaves that emerged after CMV inoculation, indicating suppression of PTGS. Both transgene mRNA sequences accumulated with the same timecourse in PTGS-suppressed CMV-infected plants (Fig. 5). However, the steady-state level of the single-stranded stuffer sequence exceeded that of the NIa dsRNA by a factor of about 5 to 15 (Fig. 5). Comparable results were obtained with the other four plants (data not shown).

All subsequent Q-RT-PCR experiments targeted the stuffer sequence because this facilitated detection of the transgene mRNA in the presence of PVY. Leaf samples from $\mathrm{C}$ and $\mathrm{C}+\mathrm{P}$ line \#16 plants were taken for RNA extraction at the same timepoints used for ELISA analysis so that virus titers and transgene mRNA levels could be correlated (Fig. 4). As in the $\mathrm{C}$ plant above (Fig. 5), in these $\mathrm{C}$ and $\mathrm{C}+\mathrm{P}_{10}$ plants, transgene mRNA was not detected in leaves 0,1 , and 2 (data not shown) but was detected starting from leaf 3 (Fig. 4). However, following high level accumulation in the first few systemic leaves of $\mathrm{C}+\mathrm{P}_{10}$ plants, transgene mRNA was no longer detected in three to four successive leaves (Fig. 4). This renewed degradation of transgene mRNA in the presence of CMV correlated with PVY accumulation in the same leaves. However, transgene mRNA levels rebounded in subsequent leaves and remained high, while PVY was no longer detectable (Fig. 4).

\section{CMV suppression \\ of PTGS does not affect accumulation of siRNAs.}

SiRNAs provide the specificity and are a hallmark of the plant's PTGS mechanism. Using riboprobes specific for the transgene NIa sequence in RNA blot analyses, similar levels of both sense and antisense polarity siRNAs were detected in line \#16 plants. These siRNAs were 23 to $25 \mathrm{nt}$ in length and were present in leaves of mock-inoculated line \#16 plants (Fig. 6A, lanes 1 to 3) but were absent from leaves of untransformed tobacco plants (Fig. 6A, lanes 11 and 12). Similar relative

Table 1. Accumulation of Cucumber mosaic virus (CMV) and Potato virus $Y$ (PVY) in a leaf fully emerged at the time of CMV inoculation in transgenic line \#16 and untransformed tobacco plants

\begin{tabular}{|c|c|c|c|c|c|}
\hline \multirow[b]{2}{*}{ Virus detected by ELISA/host plant ${ }^{b}$} & \multicolumn{5}{|c|}{ Virus inoculum $^{a}$} \\
\hline & $\mathbf{C}+\mathbf{P}_{\mathbf{0}}$ & $\mathbf{C}+\mathbf{P}_{2}$ & $\mathbf{C}+\mathbf{P}_{7}$ & $\mathbf{C}$ & $\mathbf{P}$ \\
\hline CMV/utr & 0.75 to $1.08(3)^{\mathrm{c}}$ & 0.40 to 0.92 (3) & n.d. ${ }^{d}$ & 0.32 to $0.43(2)$ & 0.01 to 0.02 (2) \\
\hline CMV/Line \#16 & 0.54 to $2.17(11)$ & 0.24 to $1.23(12)$ & 0.41 to $1.30(12)$ & 0.34 to 2.09 (10) & 0.00 to 0.01 (3) \\
\hline PVY/utr & 0.48 to 0.69 (3) & 0.37 to 0.77 (3) & n.d. & 0.00 to 0.01 (2) & 0.73 to 0.84 (2) \\
\hline PVY/Line \#16 & 0.03 to 0.18 (11) & 0.01 to $0.15(12)$ & 0.01 to $0.13(12)$ & 0.00 to 0.09 (9) & 0.03 to 0.05 (3) \\
\hline
\end{tabular}

${ }^{a}$ CMV (C), PVY (P), CMV followed by PVY on the same $\left(C+P_{0}\right), 2\left(C+P_{2}\right)$, or $7\left(C+P_{7}\right)$ days later.

${ }^{\mathrm{b}} \mathrm{CMV}$ and PVY accumulation in untransformed (utr) and transgenic line \#16 tobacco plants 2 weeks postinoculation; samples with enzyme-linked immunosorbent assay (ELISA) readings $>0.2$ after 1 -h substrate incubation were considered as positive.

${ }^{c}$ Mean of duplicate ELISA readings for the leaf two positions above the CMV-inoculated leaf (leaf 2); range of absorbance readings for the number of plants tested in brackets.

d n.d. = not determined. 
amounts of siRNAs were present in line \#16 C plants, 6 (Fig. 6A, lanes 4 to 10) and 18 (Fig 6C, lanes 11 and 12) wpiC. Comparable results were obtained with three other mock-inoculated and C plants of line \#16 (data not shown). Thus, the presence of CMV and the suppression of dsRNA-induced
PTGS did not have a significant effect on the accumulation of transgene-specific siRNAs.

NIa-specific siRNAs also accumulated to high levels in untransformed PVY-infected plants (Fig. 6B, lanes 1 to 4) and are likely to be the result of virus-induced PTGS. The levels of

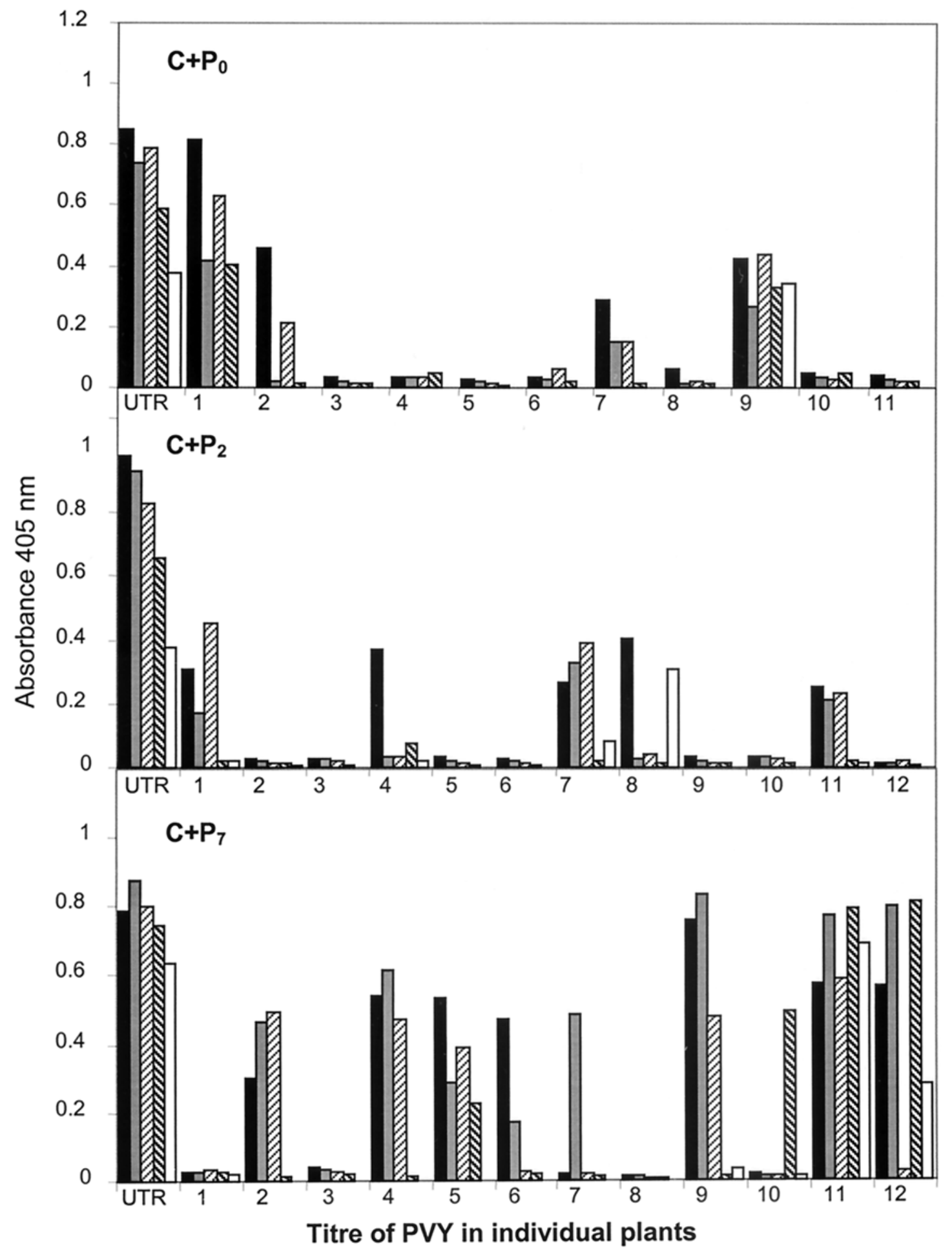

Leaf 4

Leaf 5 Leaf 6

\$IV Leaf 7

Leaf 8

Fig. 3. Serological detection of Potato virus $Y$ (PVY) in previously immune line \#16 plants following Cucumber mosaic virus (CMV) infection and suppression of posttranscriptional gene silencing. The accumulation of PVY was measured by enzyme-linked immunosorbent assay (ELISA) (absorbance $=405 \mathrm{~nm}$ after $1 \mathrm{~h}$ of substrate incubation) 6 weeks postinoculation with CMV. For each of five systemic leaves $(4$ to 8$)$ of 11 or 12 individual $\mathrm{C}+\mathrm{P}_{0}(\mathrm{PVY}$ inoculated on leaf 1 on the same day as CMV), $\mathrm{C}+\mathrm{P}_{2}\left(\mathrm{PVY}\right.$ inoculated on leaf 1, 2 days after CMV), and $\mathrm{C}+\mathrm{P}_{7}(\mathrm{PVY}$ inoculated on leaf 2, 7 days after $\mathrm{CMV}$ ) plants per treatment. UTR $=$ untransformed tobacco plants. All leaves with an ELISA reading $>0.2$ were considered infected. 
siRNA generated in response to PVY infection in untransformed tobacco appeared significantly higher than the levels of siRNA in mock- and CMV-inoculated line \#16 tobacco plants (Fig 6B, compare lanes 1 to 4 with lanes 5 to 9). On the other hand, PVY-infected $\mathrm{C}+\mathrm{P}$ line \#16 plants showed elevated levels of siRNA, similar to PVY-infected untransformed plants. For example, in $\mathrm{C}+\mathrm{P}_{7}$, plant 12 (Fig. 3), which showed breakdown of immunity, increased levels of siRNA were detected in leaves 5 and 7 (Fig. 6C, lanes 1 and 3), which accumulated PVY (Fig. 3), but not in leaf 6 (Fig. 6C, lane 2), which did not accumulate PVY (Fig. 3). In contrast, the accumulation of siRNA in $\mathrm{C}+\mathrm{P}_{7}$ plant 1 (Fig. 3), which remained immune to PVY, was comparable to that of mock, $\mathrm{C}$, or $\mathrm{P}$ plants of line \#16 (Fig. 6C, compare lanes 4 to 6 with lanes 7 to 9). In summary, the increase in PVY levels results in an increase of NIaspecific siRNAs that was not influenced by CMV. Furthermore, there was no obvious correlation between the amount of siRNAs and immunity.

\section{DISCUSSION}

We have recently demonstrated that CMV infection can suppress PTGS-based viral immunity to PVY in tobacco plants carrying a PVY dsRNA transgene (Mitter et al. 2001). Such trans-

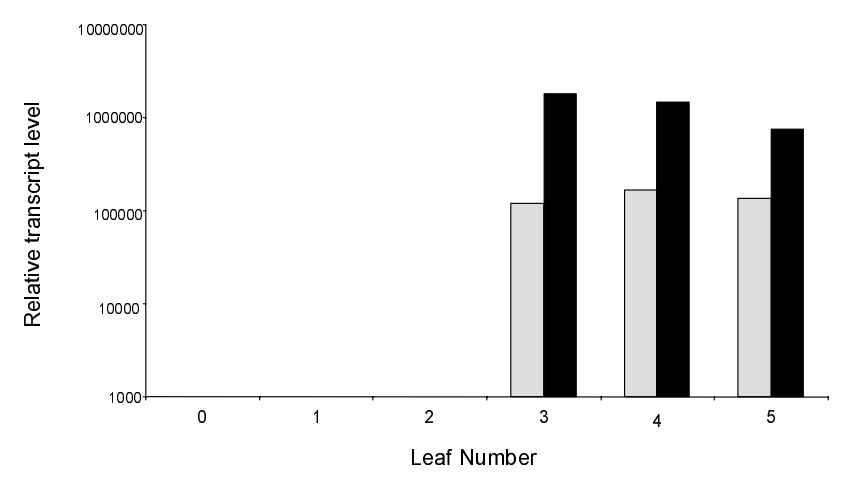

Fig. 5. Relative transgene mRNA levels for Potato virus $Y$ (PVY) NIa hairpin (gray bar) or Lettuce necrotic yellows virus (LNYV) stuffer (black bar) sequences in a Cucumber mosaic virus (CMV)-infected line \#16 plant, as determined by quantitative real time reverse transcriptasepolymerase chain reaction. CMV was inoculated on leaf 0 . Samples were taken 6 weeks postinoculation with CMV. Relative transcript level $=2^{-\Delta c t}$ in which $\Delta \mathrm{ct}=$ the difference between cycle threshold and total number of cycles.
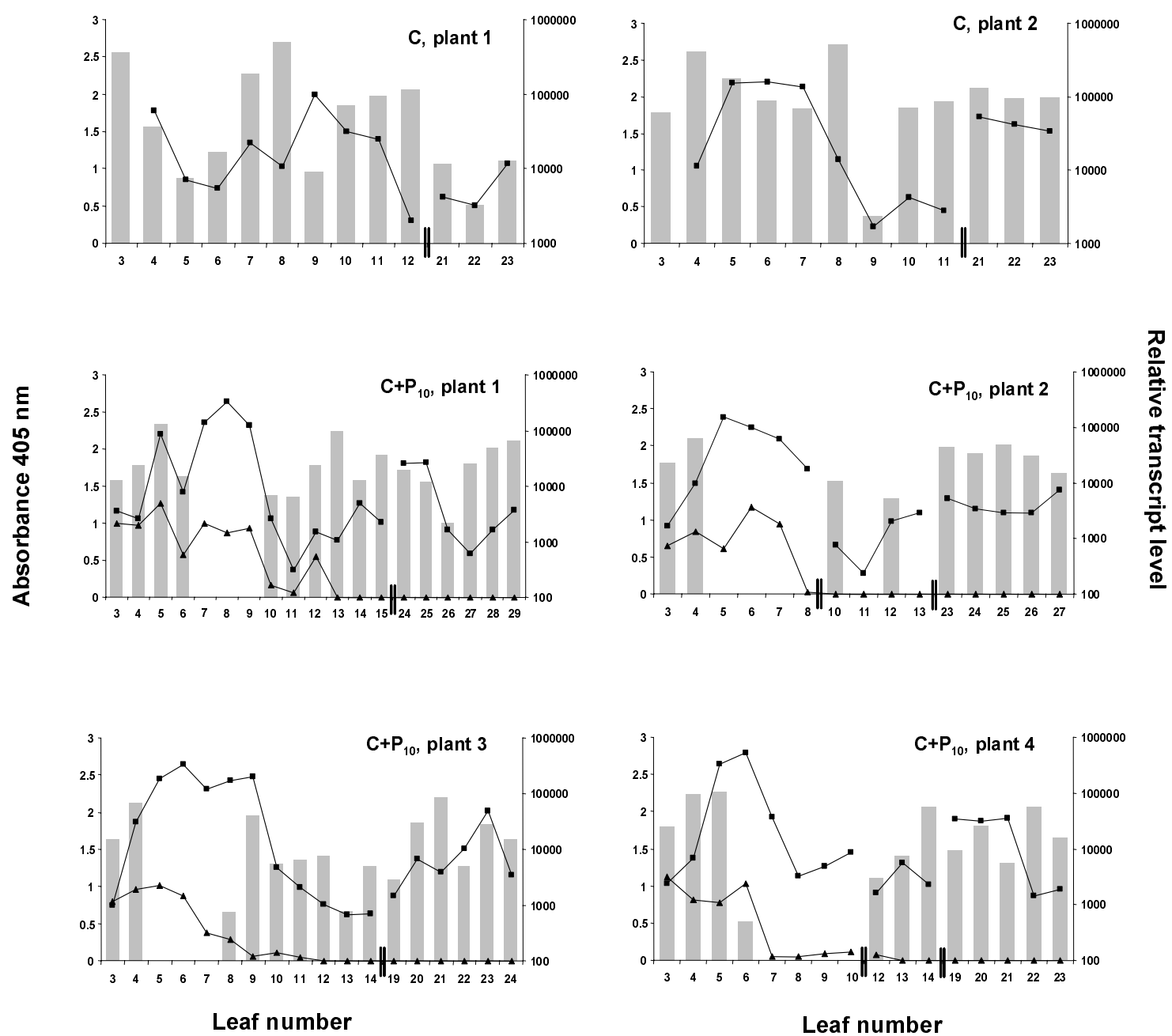

Fig. 4. Effects of Cucumber mosaic virus (CMV) suppression of dsRNA-induced posttranscriptional gene silencing on virus titers and transgene mRNA level. Transgene mRNA levels (bars) were determined by quantitative real time reverse transcriptase-polymerase chain reaction of the transcript stuffer in DNase 1-treated total RNA. Relative transcript level $=2^{-\Delta c t}$ in which $\Delta \mathrm{ct}=$ the difference between cycle threshold and total number of cycles. CMV (black squares) and PVY (black triangles) accumulation was determined by enzyme-linked immunosorbent assay (absorbance $=405 \mathrm{~nm}$ after $1 \mathrm{~h}$ substrate incubation) $3,5,10,16,19$, and 23 weeks post inoculation with CMV. Individual samples of young fully expanded leaves present at the time were tested. The leaves tested at one timepoint were not tested again. 

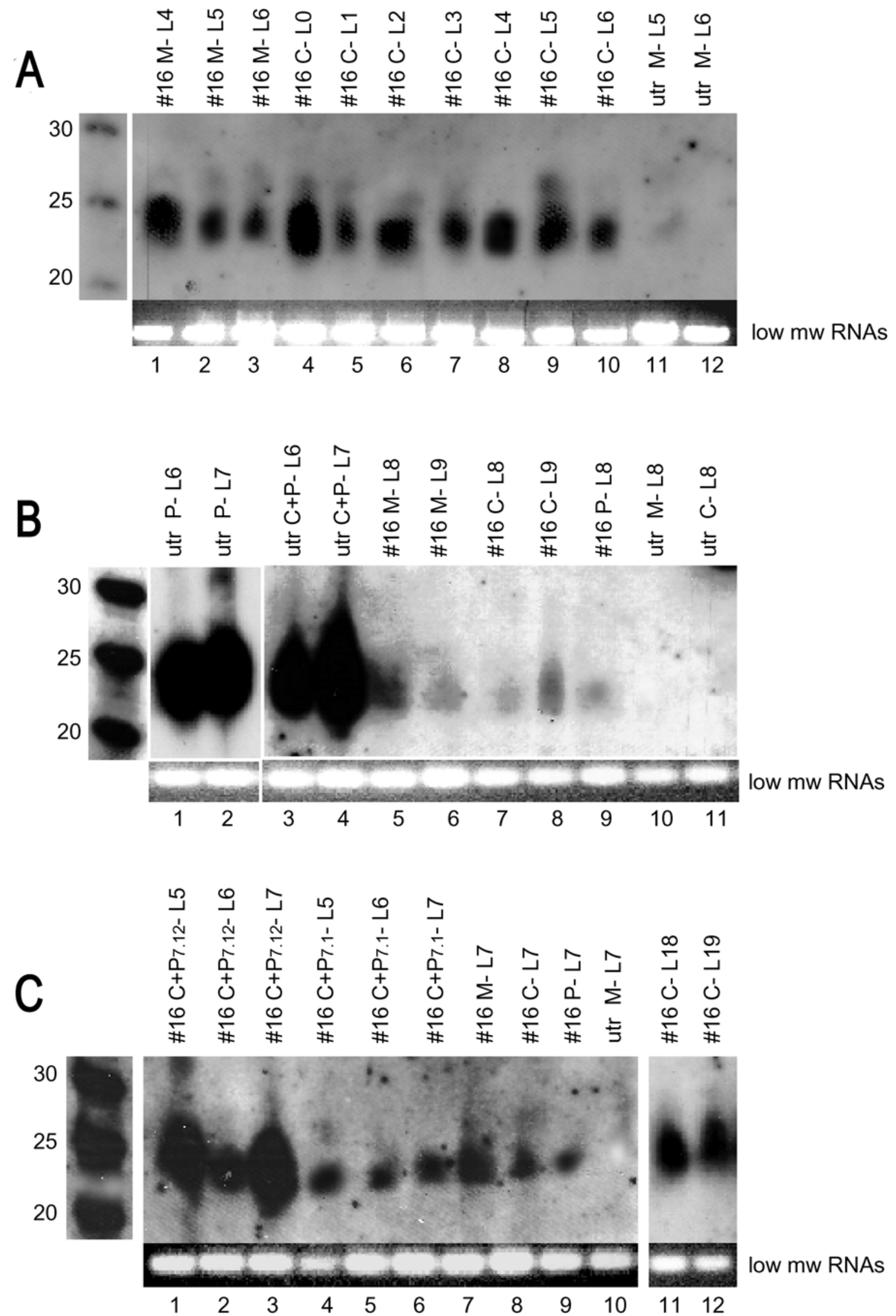

Fig. 6. RNA blot analysis of small RNAs extracted from samples taken from different leaf positions (L) of individual untransformed (utr) and line \#16 mock- (M), Cucumber mosaic virus- (C), and Potato virus $Y(\mathrm{P})$-inoculated plants. The blots were probed with a full-length antisense NIa-specific riboprobe. Migration and size (bp) of ${ }^{32} \mathrm{P}$-labeled oligonucleotides is indicated in the left margin. Equal loadings of low molecular weight RNAs separated on a $1 \%$ agarose gel and stained with ethidium bromide are shown below the blots. 
genes appear to be more effective in inducing PTGS than sense or antisense RNAs (Smith et al. 2000; Wang and Waterhouse 2002; Wang et al. 2000). To further characterize PTGS suppression and its effects on transgenic virus resistance over a longer period of time, we used a well-defined system of transgenic dsRNA-induced viral immunity. The transgenic tobacco line \#16 fulfills this requirement on the basis of several criteria: i) it carries a dsRNA transgene of the PVY NIa sequence, ii) it contains a single copy of the transgene, iii) plants are immune to PVY in homozygous as well as hemizygous states, iv) immunity to PVY is based on PTGS, as witnessed by the presence of siRNAs derived from the NIa sequence, and v) transgene mRNA transcripts are undetectable by Q-RT-PCR.

The $2 \mathrm{~b}$ protein of CMV has been shown to act as a suppressor of green fluorescent protein (GFP) silencing in Nicotiana benthamiana following agroinfiltration (Brigneti et al. 1998) and of sense transgene-induced GUS silencing in $N$. tabacum (Guo and Ding 2002). The experimental procedure of agroinfiltration-activated PTGS followed by virus vector-mediated expression of a suppressor has been very useful in demonstrating the concept of PTGS and its suppression (Qiu et al. 2002; Voinnet et al. 1999, 2000). In our model system, we studied the phenomenon of PTGS suppression as it might happen in the field when a transgenic silenced plant becomes infected by a heterologous virus that encodes a suppressor of PTGS. The results are significant from a practical point of view, as dsRNA transgene-induced PTGS is more effective and is being heralded as a new strategy for gene knock-out of undesirable traits as well as for producing virus-resistant plants.

CMV has been reported to suppress silencing of nonviral sense transgenes in newly emerging leaves of tobacco and Arabidopsis (Beclin et al. 1998). The viral dsRNA transgeneinduced immunity to PVY in line \#16 plants was similarly suppressed in leaves that had emerged after CMV inoculation. As a result, PVY-inoculation on leaves that had already formed at the time of CMV inoculation resulted in limited breakdown of immunity, e.g., $36 \%$ of $\mathrm{C}+\mathrm{P}_{0}$ and $75 \%$ of $\mathrm{C}+\mathrm{P}_{7}$ line \#16 plants (Fig. 3). When PVY was inoculated on leaves that emerged after CMV inoculation, $100 \%$ breakdown was observed. Furthermore, transgene mRNA was only detected in leaves that emerged after CMV inoculation, confirming that CMV does not reverse established PTGS. It has been reported that CMV $2 \mathrm{~b}$ protein has no effect in tissues in which PTGS is already established but prevents its initiation in newly emerging tissues (Brigneti et al. 1998; Li et al. 1999). Thus, it is likely that CMV 2b protein is responsible for breakdown of immunity in our CMV-infected dsRNA transgenic plants. Uneven CMV distribution appears to have an effect on suppression of transgene silencing and concurrent breakdown of PVY immunity in line \#16 plants. At the extreme, PVY did not accumulate in leaves where CMV was not present (Fig. 3). The presence of CMV was also essential for the suppression of a silenced sense GUS transgene (Beclin et al. 1998).

During suppression of GFP silencing by CMV 2b, some new leaves, which emerged after the first few GFP-expressing leaves, "recovered" from silencing suppression and showed no GFP expression (Lucy et al. 2000). The breakdown of PVY immunity due to CMV supported only a transient PVY infection and did not prevent recovery of the transgenic plants (Fig. 4). The recovery and PVY clearance following an initial virulent PVY infection is phenotypically similar to that reported by Lindbo and associates (1993). However, suppression of coat protein-mediated resistance to Potato virus A (PVA) by PVY infection of transgenic $N$. benthamiana did not lead to recovery, and the plants remained PVA-infected (Savenkov and Valkonen 2001).

We investigated the infection and recovery phases of the suppressed plants in terms of siRNA and transgene mRNA ac- cumulation. CMV infection did not affect NIa siRNA levels in line \#16 plants (Fig. 6). Guo and Ding (2002) reported that CMV 2 b expression did not eliminate GUS siRNAs in reactivated GUS-silenced tobacco plants; however, they noted a decrease in siRNA levels. This difference may be due to the induction of PTGS by dsRNA and sense RNA transgenes, respectively. The continued presence of NIa siRNAs in CMVinfected, suppressed tissues indicates that dsRNA degradation is incomplete and thereby does not significantly influence siRNA levels. Incomplete suppression of intracellular silencing, possibly due to CMV 2b not being expressed in every cell, has been reported by Guo and Ding (2002). It has been suggested that siRNAs provide a molecular marker for dsRNAinduced transgenic virus resistance (Kalantidis et al. 2002), but this is not the case when PTGS in such plants is suppressed by CMV 2b. Despite the presence of NIa siRNAs in CMVinfected line \#16 plants, PVY was able to replicate, though not to its full potential, providing further evidence for continued but diminished PTGS defense activity.

However, a significant increase in NIa siRNAs was witnessed in PVY-infected leaves of line \#16 plants, due to increased availability of PVY target RNA (Fig. 6). Studies of RNA interference (RNAi) in Drosophila melanogaster (Lipardi et al. 2001) and C. elegans (Sijen et al. 2001a ) suggest a target-dependent amplification of the siRNA population. A cyclic amplification process in which RNA-dependent RNA polymerase is primed by existing siRNAs has been shown to substantially augment the potency of RNAi (Sijen et al. 2001a). A similar mechanism capable of amplifying siRNAs appears to be operating in systemically silenced plants (Klahre et al. 2002). NIa siRNAs were also detected at high levels in PVYinfected untransformed plants. Accumulation of siRNAs in virus-infected plants has been shown to be due to virus-induced PTGS (Hamilton and Baulcombe 1999). In untransformed plants, PVY continues to replicate despite PTGS, whereas in line \#16 plants, the dsRNA transgene provides an additional defense factor leading to recovery.

Our results support the hypothesis that suppression of dsRNA-induced PTGS by CMV prevents efficient degradation of transgene mRNA, but they do not indicate how and where this might happen. The transgene mRNA was detected only in leaves that emerged after CMV inoculation of line \#16 plants but not in PVY-immune, silenced plants. The two components of the transgene mRNA, NIa hairpin and LNYV stuffer, accumulated with the same timecourse but to different steady-state levels (Fig. 5). DsRNA and stuffer transgene transcript sequence were detected with similar efficiency in vitro, but less dsRNA accumulated in vivo. This suggests that the dsRNA sequence was more efficiently degraded than the single-stranded stuffer sequence. In $\mathrm{C}+\mathrm{P}$ line \#16 plants, the initial phase comprised of breakdown of immunity and increased transgene mRNA levels after CMV infection. In the second phase, PVY was able to multiply. This correlated with decrease in transgene mRNA, possibly due to enhanced PTGS in the presence of target RNA or the saturation of $2 b$ function. In the third phase, plants recovered from PVY infection and the transgene mRNA levels increased once again, due to the presence of CMV. We hypothesized that renewed increase in transgene mRNA levels in recovered tissues would be indicative of the susceptible state of the plant. However, the recovered tissues of line \#16 plants were immune to PVY reinfection. Surprisingly, chronically CMV-infected line \#16 plants also could not be infected with PVY, whereas similarly treated untransformed plants of the same age supported PVY replication. This indicates that chronic CMV infection of line \#16 transgenic plants, rather than recovery from PVY infection, leads to an antiviral state, the breadth of which will need to be investigated further. 
Thus, CMV infection can induce initial breakdown of immunity in dsRNA-silenced plants. However, high transgene mRNA levels, i.e., suppression of PTGS by CMV, are not correlated with maintenance of the PVY-susceptible state.

\section{MATERIALS AND METHODS}

\section{Plants and viruses.}

Transgenic tobacco line \#16 was generated by Agrobacterium-mediated transformation of $N$. tabacum $\mathrm{cv}$. W38 with a single copy of a PVY hairpin loop construct (Mitter et al. 2001; M. Jobin-Décor and M. W. Graham, unpublished data). The construct comprised an inverted repeat of $735 \mathrm{nt}$ of the PVY NIa protease gene separated by a 362-nt stuffer sequence derived from the $4 \mathrm{~b}$ gene of LNYV under the control of a Cauliflower mosaic virus $35 \mathrm{~S}$ promoter (Fig. 1) within the backbone of the binary vector pART 27 (Gleave 1992). Transgenesis of the $\mathrm{T} 1$ and $\mathrm{T} 2$ progeny plants of this line was confirmed by PCR of the $a p h \mathrm{~A}$ gene encoding the NPTII selectable marker. CMV isolate 207 (subgroup 1A) and PVY isolate 10 (Shukla et al. 1988) were obtained from the Queensland Department of Primary Industries' plant virus collection and were maintained in cv. W 38 tobacco plants. All experiments were carried out in a glass house under physical containment.

\section{Virus inoculations and detection.}

Virus inoculum was prepared by grinding $1 \mathrm{~g}$ of infected tobacco leaf in $10 \mathrm{ml}$ of $10 \mathrm{mM}$ sodium phosphate buffer, $\mathrm{pH}$ 7.4, containing $0.1 \%$ sodium sulphite. Untransformed and line \#16 tobacco plants at the 4-leaf stage were mechanically inoculated on leaf positions as defined in Figure 2. All CMV and buffer inoculations were done on leaf 0 , and PVY inoculations in the case of $\mathrm{P}$ plants were done on leaf 1 . For coinoculations, PVY was inoculated on leaf 1 on the same day as CMV $\left(\mathrm{C}+\mathrm{P}_{0}\right)$; on leaf 1,2 days after $\mathrm{CMV}$ inoculation $\left(\mathrm{C}+\mathrm{P}_{2}\right)$; on leaf 2, 7 days after $\mathrm{CMV}$ inoculation $\left(\mathrm{C}+\mathrm{P}_{7}\right)$; and on leaf 3 , after about 10 days of CMV inoculation $\left(\mathrm{C}+\mathrm{P}_{10}\right)$. Leaves 1 and 2 were present on the plant at the time of CMV inoculation, whereas leaves 3 and onward emerged after CMV inoculation. Visual symptoms of CMV and PVY infection were recorded starting 2 wpiC.

Replication and movement of CMV and PVY in inoculated plants was confirmed by double antibody sandwich ELISA (Clark and Adams 1977). Three 8-mm diameter disks per leaf were ground in $500 \mu$ citrate buffer $(0.5 \mathrm{M}$ citrate, $0.5 \mathrm{mM}$ EDTA, $0.05 \%$ Tween $20,0.2 \%$ bovine serum albumin, $\mathrm{pH} 8.0$ ) and were briefly centrifuged, and duplicate $100-\mu \mathrm{l}$ samples were tested. Commercial ELISA kits for detection of CMV and PVY (Sanofi Diagnostics Pasteur, Chaska, MN, U.S.A.) were used with some modifications. Antibodies and alkaline phosphatase conjugate were diluted 1:200 in coating buffer and PBS-Tween containing 1\% skim milk, respectively. Substrate absorbance was measured at $405 \mathrm{~nm}$ after $1 \mathrm{~h}$ of incubation, using an ELISA plate reader (Dynex Technologies, Chantilly, VA, U.S.A.).

\section{Q-RT-PCR.}

Total plant RNA was extracted from $100 \mathrm{mg}$ of leaf material using the RNeasy plant mini kit (Qiagen, Clifton Hill, Victoria, Australia). On-column digestion of DNA during RNA purification was done with RNase-free DNase 1 (Qiagen). To ensure complete DNA digestion, the eluted RNA samples were subjected to a second DNase treatment. DNase was inactivated by adding $0.5 \mathrm{mM}$ EDTA and heating at $65^{\circ} \mathrm{C}$ for $15 \mathrm{~min}$. In vitro transcripts of the transgene were generated from a plasmid carrying the dsRNA transgene, us- ing the MAXIscript T3 in vitro transcription kit (Ambion, Austin, TX,U.S.A.). A 10 -fold dilution series $\left(10^{4}\right.$ to $10^{8}$ molecules) of RNA transcripts was analyzed for template quantification of NIa and LNYV sequences. Analysis was done by Q-RT-PCR, using TaqMan chemistry (Applied Biosystems, Melbourne, Australia). Oligonucleotide primers and probes were designed using Primer Express software (Applied Biosystems) to target the NIa hairpin and LNYV stuffer sequence in the transgene transcript. The primers NIa Taq F1 (5'-TGCATCGTCGATCATCACAGA- 3'), NIa Taq R1 (5'TTTCAATCCAATGCTTCCAGAAT- $\left.3^{\prime}\right)$, LNYV 4b F (5'TGCCAAGAAGAAGGAGCTAAA-3'), and LNYV 4b R (5'-TGGGACTTGCCTCATTATAACA-3') were synthesized by Sigma Genosys (Sydney, Australia). The 5'FAM-labeled TaqMan probes for NIa (5'-CAAGCCCACCACTTACAATATACCGGGC-3') and LNYV (5'-AATCGTAACGTCTTCCGGATCGAACA-3') were supplied by Applied Biosystems. The TaqMan one-step RT-PCR kit and a model 7700 Sequence detector system (Applied Biosystems) were used. The RT-PCR reaction $(25 \mu \mathrm{l})$ was optimized to contain $50 \mathrm{ng}$ of template plant RNA, $100 \mathrm{nM}$ each forward and reverse primers, and $100 \mathrm{nM}$ TaqMan probe. Thermal cycling conditions were $48^{\circ} \mathrm{C}$ for $30 \mathrm{~min}, 95^{\circ} \mathrm{C}$ for $10 \mathrm{~min}, 45$ cycles of $95^{\circ} \mathrm{C}$ for $15 \mathrm{~s}$ and $60^{\circ} \mathrm{C}$ for $1 \mathrm{~min}$, followed by $25^{\circ} \mathrm{C}$ for $2 \mathrm{~min}$. All reactions were carried out in duplicate, and reactions lacking reverse transcriptase were included to monitor for any DNA contamination. RNA extracted from LNYV-infected $N$. glutinosa was used as a positive control, and RNase-free water and RNA extracted from untransformed tobacco were used as negative controls. Relative transcript levels were calculated as $\mathrm{rtl}=2^{-\Delta \mathrm{Ct}}$, where $\Delta \mathrm{Ct}$ is the difference between cycle threshold and total number of cycles.

\section{Extraction and detection of siRNAs.}

Total RNA extraction and enrichment for low molecular weight RNAs was done as described by Han and Grierson (2002). Sense- and antisense-specific riboprobes corresponding to the NIa gene were generated using the MAXIscript T7 in vitro transcription kit (Ambion, Austin, TX, U.S.A.). Low molecular weight RNAs were visualized on ethidium bromide-stained $1 \%$ agarose gels as approximately 250-bp bands, to enable equal loading for siRNAs. siRNAs were separated on $15 \%$ polyacrylamide, $7 \mathrm{M}$ urea, and TBE (Sambrook et al. 1989) gels, were transferred onto Hybond NX membrane (Amersham Biosciences, Piscataway, NJ, U.S.A.) by electrophoretic transfer using a Trans-Blot semidry apparatus (Bio-Rad, Regents Park, Australia), and were UV-crosslinked. Oligonucleotide size markers of $20 \mathrm{bp}, 25$ $\mathrm{bp}$, and $30 \mathrm{bp}$ were labeled with ${ }^{32} \mathrm{P}-\mathrm{UTP}$, using T4 polynucleotide kinase (MBI Fermentas, Hanover, MD, U.S.A.). Membranes were prehybridized at $50^{\circ} \mathrm{C}$ for $2 \mathrm{~h}$ and hybridized at $42^{\circ} \mathrm{C}$ overnight, using Superhyb solutions (Molecular Research Center Inc., Cincinnati, OH, U.S.A.). The blots were washed at $50^{\circ} \mathrm{C}$ with $2 \times \mathrm{SSC}(1 \times \mathrm{SSC}$ is $0.15 \mathrm{M} \mathrm{NaCl}$ plus $0.015 \mathrm{M}$ sodium citrate), $0.5 \%$ sodium dodecyl sulfate (SDS) for $10 \mathrm{~min}, 1 \times \mathrm{SSC}, 0.5 \% \mathrm{SDS}$ for $15 \mathrm{~min}$, and $0.5 \times$ SSC, $0.5 \%$ SDS for $10 \mathrm{~min}$, and were exposed to AGFA Curix X-ray film between intensifying screens at $-70^{\circ} \mathrm{C}$.

\section{ACKNOWLEDGMENTS}

We thank V. Mitter and E. MacCallum for expert technical assistance, A. Mallory for the siRNA isolation method and advice, and M. Jobin-Décor and M.W. Graham for kindly providing us with seeds of the transgenic tobacco line \#16. We are grateful to M. W. Graham for critical discussions, B. Carroll for critical comments, and J. Manners for his continued support. This study was supported by the Cooperative Research Center for Tropical Plant Protection. 


\section{LITERATURE CITED}

Bass, B. L. 2000. Double-stranded RNA as a template for gene silencing. Cell 101:235-238.

Baulcombe, D. C. 1999. Viruses and gene silencing in plants. Arch. Virol. Suppl. 15:189-201.

Beclin, C., Berthome, R., Palauqi, J. C., Tepfer, M., and Vaucheret, H. 1998. Infection of tobacco or Arabidopsis plants by CMV counteracts systemic post-transcriptional silencing of nonviral (trans) genes. Virology 252:313-317.

Beclin, C., Boutet. S., Waterhouse, P., and Vaucheret, H. 2002. A branched pathway for transgene-induced RNA silencing in plants. Curr. Biol. 12:684-688.

Bernstein, E., Caudy, E. E., Hammond, S. M., and Hannon, G. J. 2001. Role for a bidentate ribonuclease in the initiation step of RNA interference. Nature 409:363-366.

Brigneti, G., Voinnet, O., Li, W. X., Ji, L. H., Ding, S., and Baulcombe, D. C. 1998. Viral pathogenicity determinants are suppressors of transgene silencing in Nicotiana benthamiana. EMBO (Eur. Mol. Biol. Organ.) J. 17:6739-6746.

Carmell, M. A., Zhang, L., Conklin, D. C., and Hannon, G. J. 2003. Germline transmission of RNAi in mice. Nature 10:91-92

Carrington, J. C., Kasschau, K. D., and Johansen, L. K. 2001. Activation and suppression of RNA silencing by plant viruses. Virology 281:1-5.

Chuang, C. F., and Meyerowitz, E. M. 2000. Specific and heritable genetic interference by double-stranded RNA in Arabidopsis thaliana. Proc. Natl. Acad. Sci. U.S.A. 97:4985-4990.

Clark, M. F., and Adams, A. N. 1977. Characteristics of the microplate method of enzyme-linked immunosorbent assay for the detection of plant viruses. J. Gen. Virol. 34:475-483.

Ding, S. W. 2000. RNA silencing. Curr. Opin. Biotech. 11:152-156.

Djikeng, A., Shi, H., Tschudi, C., and Ullu, E. 2001. RNA interference in Trypanosoma brucei: Cloning of small interfering RNAs provides evidence of retroposon-derived 24-26 nt RNAs. RNA 7:1-9.

Dougherty, W. G., and Parks, T. D. 1995. Transgenes and gene suppression: Telling us something new? Curr. Opin. Cell Biol. 7:399-405.

Fagard, M., and Vaucheret, H. 2000. Systemic silencing signals. Plant Mol. Biol. 43:285-293.

Gleave, A. P. 1992. A versatile binary vector system with a T-DNA organisational structure conducive to efficient integration of cloned DNA into the plant genome. Plant Mol. Biol. 20:1203-1207.

Guo, H. S., and Ding, S. W. 2002. A viral protein inhibits the long range signalling activity of gene silencing signal. EMBO (Eur. Mol. Biol. Organ.) J. 21:398-407.

Hamilton, J. H., and Baulcombe, D. C. 1999. A species of small antisense RNA in post-transcriptional gene silencing in plants. Science 286:950952

Hammond, S. M., Bernstein, E., Beach, D., and Hannon, G. J. 2000. An RNA-directed nuclease mediates post transcriptional gene silencing in Drosophila cells. Nature 404:293-296.

Han, Y., and Grierson, D. 2002. Relationship between small antisense RNAs and aberrant RNAs associated with sense transgene mediated gene silencing in tomato. Plant J. 29:509-519.

Kalantidis, K., Psaradakis, S., Tabler, M., and Tsagris, M. 2002. The occurrence of CMV-specific short RNAs in transgenic tobacco expressing virus-derived double-stranded RNA is indicative of resistance to the virus. Mol. Plant-Microbe Interact. 15:826-833.

Klahre, U., Crete, P., Leuenberger, S. A., Iglesias, V. A. Meins, F., Jr 2002. High molecular weight RNAs and small interfering RNAs induce systemic post transcriptional gene silencing in plants. Proc. Natl. Acad. Sci. U.S.A. 99:11981-11986.

Li, W. X., and Ding, S. W. 2001. Viral suppressors of RNA silencing. Curr. Opin. Biotech. 12:150-154

Li, H. W., Lucy, A. P., Guo, H. S., Li, W. X., Ji, L. H., Wong, S. M., and Ding, S. W. 1999. Strong host resistance targeted against a viral suppressor of plant gene silencing defence mechanism. EMBO (Eur. Mol. Biol. Organ.) J. 18:2683-2691.

Lindbo, J. A., Silva-Rosales, L., Proebsting, W. M., and Dougherty, W. G. 1993. Induction of a highly anitviral state in transgenic plants: Implications for regulation of gene expression and virus resistance. Plant Cell 5:1749-1759.

Lipardi, C., Wei, Q., and Paterson. B. M. 2001. RNAi as random degradative PCR: siRNA primers convert mRNA into dsRNAs that are degraded to generate new siRNAs. Cell 107:297-307.

Llave, C., Kasschau, K., and Carrington, J. 2000. Virus-encoded suppressor of post transcriptional gene silencing targets in maintenance step in the silencing pathway. Proc. Natl. Acad. Sci. U.S.A. 97:13401-13406.

Lucy, A. P., Guo, H. S., Li, W. X., and Ding, S. W. 2000. Suppression of post transcriptional gene silencing by a viral protein localised in the nucleus. EMBO (Eur. Mol. Biol. Organ.) J. 19:1672-1680.
Mallory, A. C., Ely, L., Smith, T. H., Marathe, R., Anandlakshmi, R. Faggard, M., Vaucheret, H., Pruss, G., Bowman, L., and Vance, V. B. 2001. HC-Pro suppression of transgene silencing eliminates the small RNAs but not transgene methylation or the mobile signal. Plant Cell 13:571-583.

Marathe, R. W., Anandalakshmi, R., Smith, T. H., Pruss, G. J., and Vance, V. B. 2000. RNA viruses as inducers, suppressors and targets of post transcriptional gene silencing. Plant Mol. Biol. 43:295-306.

Matzke, M. A., Matzke, A. J. M., and Kooter, J. M. 2001. RNA: Guiding gene silencing. Science 293:1080-1083.

Mitter, N., Sulistyowati, E., Graham, M. W., and Dietzgen, R. G. 2001. Suppression of gene silencing: A threat to virus-resistant transgenic plants? Trends Plant Sci. 6:246-247.

Parrish, S., Fleenor, J., Xu, S., Mello, C., and Fire, A. 2000. Functional anatomy of a dsRNA trigger. Differential requirement for the two trigger strands in the RNA interference. Mol. Cell 6:1077-1087.

Qiu, W., Park, J.-W., and Scholthof, H. B. 2002. Tombusvirus P19-mediated suppression of virus-induced gene silencing is controlled by genetic and dosage features that influence pathogenicity. Mol. PlantMicrobe Interact. 15:269-280.

Que, Q., Wang, H. Y., English, J. J., and Jorgenson, R. A. 1997. The frequency and degree of cosuppression by sense chalcone synthase transgenes are dependent on transgene promoter strength and are reduced by premature nonsense codons in the transgene coding sequence. Plant Cell 9:1357-1368.

Sambrook, J., Fritsch, E. F., and Maniatis, T. 1989. Molecular Cloning : A Laboratory Manual. 2nd ed. Cold Spring Harbor Laboratory. Cold Spring Harbor, NY, U.S.A.

Savenkov, E. I., and Valkonen, J. P. T. 2001. Coat protein gene-mediated resistance to Potato virus A in transgenic plants is suppressed following infection with another potyvirus. J. Gen. Virol. 82:2275-2278.

Sharp, P. 2001. RNA interference. Genes Dev. 15:485-490.

Shukla, D. D., Thomas, J. E., McKern, N. M., Tracy, S. L., and Ward, C. W. 1988. Coat protein of potyviruses. 4. Comparison of biological properties, serological relationships, and coat protein amino acid sequences of four strains of potato virus Y. Arch. Virol. 102:207-219.

Sijen, T., Fleenor, J., Simmer, F., Thijssen, K. L., Parrish, S., Timmons, L., Plasterk, R. H. A., and Fire, A. 2001a. On the role of RNA amplification in dsRNA-triggered gene silencing. Cell 107:465-476.

Sijen, T., Vijn, I., Rebocho, A., van Blokl, R., Roelofs, D., Mol, J. N., and Kooter, J. M. 2001b. Transcriptional and post-transcriptional gene silencing are mechanistically related. Curr. Biol. 11:436-440.

Smith, N. A., Singh, S. P., Wang, M. B., Stoutjesdijk, P. A., Green, A, G., and Waterhouse, P. M. 2000. Total silencing by intron-spliced hairpin RNAs. Nature 407:319-320.

Stam, M., Viterbo, A., Mol, J. N., and Kooter, J. M. 1998. Position-dependent methylation and transcriptional silencing of transgenes in inverted T-DNA repeats: Implications for post transcriptional silencing of homologous host genes in plants. Mol. Cell. Biol. 18:6165-6177.

Vaucheret, H., Nussaume, L., Palauqui, J. C., Quillere, I., and Elmayan, T. 1997. A transcriptionally active state is required for post transcriptional silencing (cosuppression) of nitrate reductase host genes and transgenes. Plant Cell 9:1357-1368.

Voinnet, O. 2001. RNA silencing as a plant immune system against viruses. Trends Genet. 17:449-459.

Voinnet, O., Pinto, Y. M., and Baulcombe, D. C. 1999. Suppression of gene silencing: A general strategy used by diverse DNA and RNA viruses of plants. Proc. Natl. Acad. Sci. U.S.A. 96:14147-14152.

Voinnet, O., Lederer, C., and Baulcombe, D. C. 2000. A viral movement protein prevents spread of the gene silencing signal in Nicotiana benthamiana. Cell 103:157-167.

Wang, M. B., and Waterhouse, P. M. 2002. Applications of gene silencing in plants. Curr. Opin. Plant Biol. 5:146-150.

Wang, M. B., Abbott, D., and Waterhouse, P. M. 2000. A single copy of a virus derived transgene encoding hairpin RNA gives immunity to Barley yellow dwarf virus. Mol. Plant Pathol. 1:347-356.

Waterhouse, P. M., Graham, M. W., and Wang, M. B. 1998. Virus resistance and gene silencing in plants can be induced by simultaneous expression of sense and antisense RNA. Proc. Natl. Acad. Sci. U.S.A. 95:13959-13964.

Waterhouse, P. M., Wang, M. B., and Lough, T. 2001. Gene silencing as an adaptive defence against viruses. Nature 411:834-842.

Wesley, S. V., Helliwell, C. A., Smith, N. A., Wang, M. B., Rouse, D. T. Liu, Q., Gooding, P. S., Singh, S. P., Abbott, D., Stoutjesdijk, P. A., Robinson, S. P., Gleave, A. P., Green, A. G., and Waterhouse, P. M 2001. Construct design for efficient, effective and high-throughput gene silencing in plants. Plant J. 27:581-590.

Zamore, P., Tuschl, T., Sharp, P., and Bartel, D. 2000. RNAi: Double stranded RNA directs the ATP-dependent cleavage of mRNA at 21 to 23 nucleotide intervals. Cell 101:25-33. 